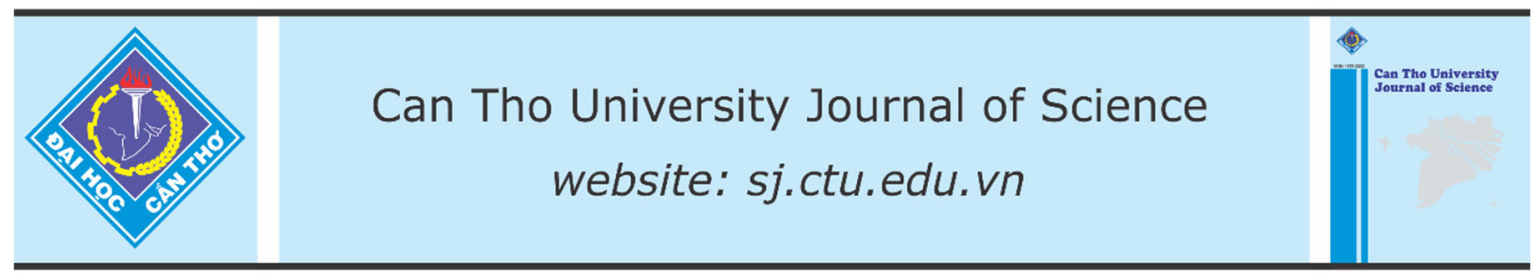

DOI: $10.22144 / c t u . j e n .2019 .003$

\title{
Escherichia coli infection in ducks in the Mekong Delta: Bacterial isolation, serogroup distribution and antibiotic resistance
}

\author{
Ho Thi Viet Thu ${ }^{1 *}$, Doan Tran Loan $\mathrm{Anh}^{1}$ and Le Van Dong ${ }^{2}$ \\ ${ }^{I}$ College of Agriculture and Applied Biology, Can Tho University, Vietnam \\ ${ }^{2}$ Tra Vinh University, Vietnam \\ ${ }^{*}$ Correspondence: Ho Thi Viet Thu (email: htvthu@ctu.edu.vn)
}

\section{Article info.}

Received 13 Jun 2018

Revised 03 Nov 2018

Accepted 29 Mar 2019

\section{Keywords}

Antibiotic, duck, E. coli, resistance, serogroup

\begin{abstract}
An investigation on duck Escherichia coli infection was carried out by examination of 241 suspicious colibacillosis outbreaks from 1 city and 4 provinces in the Mekong Delta. The study procedure involves several steps including bacterial isolation and identification, O serogroup typing and antibiotic resistant determination. The results showed that 990 from 994 ducks were confirmed to be infected by E. coli. E. coli bacteria were found from feces in almost diseased ducks (99.0\%) and many organ samples; the highest rate of positive isolates was reported from livers (78.3\%), followed by lungs (71.8\%), spleens $(67.4 \%)$, and the lowest one was in bone marrows (58.9\%). The typing of 300 E. coli isolates with 10 important groups of mono $O$ antisera revealed that 265 isolates were identified and belonged to 10 O serogroups. The most commonly isolated O group was O2 (16.7\%), followed by O78 (15.0\%), O81 (9.7\%), O35 (9.3\%), O1 (8.0\%), O36 (7.0\%), O111 (7.7\%), O92 (5.7\%), O18 (5.3\%), and the lowest one was $093(4.0 \%)$. A total of 659 E. coli isolates were tested for their sensitivity to commonly used antibiotics, these avian pathogenic E. coli isolates demonstrated moderate to high resistances (20.2 $\%$ to $67.4 \%$ ) to $7 / 15$ antibiotics tested, and very little amikacin and fosfomycin resistances (3.0 and 6.4\%). It is imperative that susceptibility tests should be carried out on infecting pathogen prior to treatment of ducks colibacillosis in field in order to avoid treatment failure and reduce selective pressure that could result in spreading avian pathogenic $E$. coli in the environment.
\end{abstract}

Cited as: Thu, H.T.V., Anh, D.T.L. and Dong, L.V., 2019. Escherichia coli infection in ducks in the Mekong Delta: Bacterial isolation, serogroup distribution and antibiotic resistance. Can Tho University Journal of Science. 11(1): 24-29.

\section{INTRODUCTION}

Avian colibacillosis is a complicated disease with many localized and systemic infections caused by avian pathogenic Escherichia coli (APEC) including colisepticemia, salpingitis, anopthalmitis, osteoarthiritis, synovitis, coligranuloma, airsaculitis, and cellulitis. Nowadays, there is general agreement that avian colibacillosis is one of the leading causes of mortality and morbidity associated with economic losses in the poultry production throughout the world (Roshdy et al., 2012; Zhuang et al., 2014). Economic losses can be due to decreased hatching rates, decreased egg production, mortality, lowered production, carcass condemnation at slaughter and costs associated with 
treatment, and prophylaxis. More than 1,000 serotypes are known, but only a few are considered as important in avian pathology. Earlier studies by Sojka and Carnaghan (1961) identified the serotypes $\mathrm{O} 1, \mathrm{O} 2, \mathrm{O} 35$, and $\mathrm{O} 78$ as the most dominated. However, recent studies have shown that the serotypes $\mathrm{O} 1, \mathrm{O} 2$, and $\mathrm{O} 78$ are widely spread and represent $15-61 \%$ of the isolates, yet other types still exist (Dho-Moulin and Fairbrother, 1999). In Vietnam, duck production is well developed in the Mekong Delta, accounting for $48.3 \%$ of the poultry population in Vietnam (FAO, 2008). E. coli infection in ducks was recognized as a popular and important duck disease in the Mekong Delta with $74.50 \%$ of ducks in Long An infected (Nguyen Trong Phuoc, 1997), and mortality of E. coli infection ducks could be high as 40 to $50 \%$ (Nguyen Xuan Binh et al., 2000). In addition, the frequent use of antibiotics in drinking water and duck feed for preventive and treatment purposes which have been responsible for selective pressure of $E$. coli bacteria lead to a lot of $E$. coli strains develop antibiotic resistance to multi-antibiotics (Vo Thi Tra An et al., 2010; Tran Thi Thuy Giang et al., 2014), and $E$. coli infections become harder to treat. Another concern is that E. coli bacteria are the most popular agents which cause food poisoning, and they are transmitted to human by food chains from animal products including duck eggs and meat. The main purpose of this study was to examine the incidence of $\mathrm{O}$ serogroups, antibiotic resistance of E. coli in diseased ducks in the Mekong Delta.

The result will be useful information in disease control, and contribution of E. coli antibiotic resistant alleviation strategy.

\section{MATERIAL AND METHODS}

\subsection{Bacterial isolation and identification}

\subsubsection{Sample collection}

E. coli infection suspicious ducks from 241 flocks from Can Tho city and 4 provinces (Vinh Long, Hau Giang, Dong Thap and Tra Vinh) were collected and screened for $E$. coli infection. In each flock, 4-6 diseased ducks were sampled, and E. coli bacteria were isolated from internal organs (lung, liver, spleen), bone marrow, and feces from diseased ducks.

\subsubsection{E. coli isolation and identification}

E. coli was cultured on MacConkey and nutrient agar (NA) medium for morphological characterization. After 24 hrs, all E. coli colonies were pink, round and convex on MacConkey medium, 3-5 of these colonies were collected for growing on NA. After $24 \mathrm{hrs,} \mathrm{E}$. coli appeared creamy white on NA medium. E. coli were identified by biochemical tests with Indole, Methyl Red, Voges-Proskauer, Simmons citrate from Merck Co (Germany) according to Bryan et al. (2013). Duck was confirmed to be infected with $E$. coli when E. coli bacteria were found at least from 1 internal organ or bone marrow.

\subsection{O-serogroup typing}

Ten E. coli O-antisera (O1, O2, O18, O35, O36, O78, O81, O92, O93, O111) antigens (SSI Diagnostica, Denmark) were available for testing. Sixty representatives of APEC isolates in each province or city were chosen for sero-typing. Totally, 300 APEC isolates were typed by screening the potential O-serotype by slide agglutination test, according to the manufacturer's.

\subsection{Antibiotic resistant examination}

Antibiotic resistant examination was studied by antibiotic susceptibility tests with 15 antibiotics commonly used in poultry farming in the Mekong delta by antibiotics discs of amikacin $(30 \mu \mathrm{g})$, ampicillin $(10 \mu \mathrm{g})$, ceftazidime/clavulanic acid $(30 \mu \mathrm{g})$, cefuroxime $(30 \mu \mathrm{g})$, ciprofloxacin $(5 \mu \mathrm{g})$, colistin $(10 \mu \mathrm{g})$, doxycylin $(30 \mu \mathrm{g})$, florfenicol $(30 \mu \mathrm{g})$, fosfomycin $(200 \mu \mathrm{g})$, gentamycin $(10 \mu \mathrm{g})$, norfloxacin $(10 \mu \mathrm{g})$, ofloxacin $(5 \mu \mathrm{g})$, streptomycin $(10 \mu \mathrm{g}), \quad$ tetracycline $(30 \mu \mathrm{g}), \quad$ and trimethoprim/sulfamethoxazole $\quad(1,25 / 23,75 \mu \mathrm{g})$ distributed by Nam Khoa Biotek Co. Ltd (Vietnam). In this study, two to three isolates from each outbreak were chosen for testing. Totally, 569 APEC isolates were used in antibiotic susceptibility tests.

Antimicrobial susceptibility was determined by agar diffusion method according to Bauer et al. (1966). Pure cultures of $E$. coli were grown overnight in NA at $37^{\circ} \mathrm{C}$ in $24 \mathrm{hrs}$, then the bacterial concentration was adjusted based on 0.5 McFarland turbidity, approximately bacterial suspension of $1.5 \times 10^{8}$ bacteria $/ \mathrm{ml}$. One hundred $\mu \mathrm{L}$ of the culture suspension was spread onto each Mueller Hinton Agar (Merck, Germany) plate surface, and three or four antimicrobial discs were placed on the surface of the agar plate. These plates were incubated at $37^{\circ} \mathrm{C}$ for 16 to $20 \mathrm{hrs}$. The results were interpreted as sensitive, intermediate, or resistant based on aseptic diameter measurement according to the Clinical and Laboratory Standards Institute (CLSI, 2017).

\section{Statistical analysis}

The data obtained were analyzed by Minitab software 13.2 (Ryan et al., 2000), using Goodness 
to fit test and Chi square to assess significant differences in the prevalence of serogroups and antibiotic resistance rates.

\section{RESULTS AND DISCUSSIONS}

Conventional diagnosis method for the disease is based on E. coli isolation and identification from typical lesion of colibacillosis (Barnes et al., 2008), and positive isolation and identification of $E$. coli from visceral organ of suspected ducks is an indication of colibacillosis. The results of confirmed colibacillosis by $E$. coli isolation and identification showed that 226 out of $241(93.8 \%)$ suspected colibacillosis duck flocks were confirmed to be colibacillosis flocks, and 990 from 994 of examined ducks $(99.6 \%)$ in colibacillosis flocks were colibacillosis ducks. Since the definite aim of the study is to assert colibacillosis ducks and flocks by $E$. coli isolation and identification from suspicious clinical cases based on typical symptoms and lesions, the percentages of positive ducks and flocks were nearly $100.0 \%$, and there was no significant difference between positive duck percentages of surveyed areas.

Table 1: Results of confirmed colibacillosis diagnosis by $E$. coli isolation and identification

\begin{tabular}{lrrrr}
\hline City/ provinces & $\begin{array}{r}\text { No. colibacillosis flocks/ } \\
\text { No. examined flocks colibacillosis flocks }\end{array}$ & $\begin{array}{r}\text { No. ducks in } \\
\text { No. colibacillosis } \\
\text { ducks }\end{array}$ & (\%) \\
\hline Can Tho & $49 / 52$ & 200 & 200 & 100.0 \\
Hau Giang & $52 / 55$ & 202 & 202 & 100.0 \\
Vinh Long & $42 / 48$ & 200 & 200 & 100.0 \\
Dong Thap & $43 / 45$ & 214 & 213 & 99.5 \\
Tra Vinh & $40 / 41$ & 178 & 175 & 98.3 \\
Total & $226 / 241$ & 994 & 990 & 99.6 \\
\hline
\end{tabular}

Table 2: Incidence of $E$. coli recovered from feces and internal organs of colibacillosis ducks

\begin{tabular}{lrrr}
\hline Duck sample & No. of tested & $\begin{array}{r}\text { No. of } \\
\text { positive }\end{array}$ & (\%) \\
\hline Feces & 990 & 980 & $99.0^{\mathrm{a}}$ \\
Liver & 990 & 775 & $78.3^{\mathrm{b}}$ \\
Lung & 990 & 711 & $71.8^{\mathrm{c}}$ \\
Spleen & 990 & 667 & $67.4^{\mathrm{d}}$ \\
Bone marrow & 990 & 583 & $58.9^{\mathrm{e}}$ \\
\hline
\end{tabular}

Values in the same column with different letter are significantly different $(P<0.05)$

E. coli bacteria were found from feces in almost diseased ducks (99\%) and all types of organ samples collected, the highest rate of positive isolates was reported from livers $(78.3 \%)$, followed by lungs $(71.8 \%)$, spleens $(67.4 \%)$, and the lowest one was in bone marrows $(58.9 \%)$. Avian colibacillosis is a complicated disease with many localized and systemic infections depending on bacterial localization. Primary enteritis is a common manifestation of $E$. coli infection in mammals, but it is considered rare in birds. The very high percentage of $E$. coli recovered from diseased duck feces due to $E$. coli is a common inhabitant of the duck intestine, and it is widely disseminated in fecal materials so that the presence of $E$. coli from duck feces may be from septicemia colibacillosis, E. coli primary enteritis, and even healthy ducks. In ducks, coliform septicemia is quite popular, in this case E. coli (usually O78) can be recovered from any of internal organ (Leibovitz, 1972). Since, localization of $E$. coli in bone and synovial tissue was a common sequel of septicemia, the frequency of positive isolates was lower than from other internal organs.

Table 3: O-serogroup distribution of APEC isolates of ducks $(n=300)$

\begin{tabular}{lrc}
\hline Serotype & No. of positive & Prevalence (\%) \\
\hline O1 & 24 & 8.0 \\
O2 & 50 & $16.7^{* *}$ \\
O18 & 16 & 5.3 \\
O35 & 28 & 9.3 \\
O36 & 21 & 7.0 \\
O78 & 45 & $15.0^{*}$ \\
O81 & 29 & 9.7 \\
O92 & 17 & 5.7 \\
O93 & 12 & 4.0 \\
O111 & 23 & 7.7 \\
Others & 35 & 11.7 \\
\hline \multicolumn{2}{|}{} \\
\hline
\end{tabular}

Prevalence with $*$ is significant difference at level $(P=<0.05)$ and with $* *(P=<0.001)$

In this study, $10 \mathrm{O}$-serogroups were identified from 300 APEC isolates. Five serogroups $(\mathrm{O} 1, \mathrm{O} 2, \mathrm{O} 35$, $\mathrm{O} 78$ and $\mathrm{O} 81$ ) accounted for $58.7 \%$ of pathogenic strains. Among these, $\mathrm{O} 2$ and $\mathrm{O} 78$ were predominant serogroups, and the prevalence of $\mathrm{O} 78$ group (15.0\%) and $\mathrm{O} 2$ group (16.7\%) showed significant differences with other O-type ones. This result was different from recent reports of colibacillosis in Muscovy ducks (Nguyen Thi Lien Huong, 2017) and from Bau and Dom ducks in the north of Vietnam, in which $\mathrm{O} 2$ and $\mathrm{O} 78$ were not 
detected (Dang Thi Vui and Nguyen Ba Tiep, 2016), but it was quite similar to the study results in chickens in Ho Chi Minh city (To Minh Chau et al., 2002), 3 determined serotypes of $E$. coli isolates were $\mathrm{O} 1: \mathrm{K} 1, \mathrm{O} 2: \mathrm{K} 1, \mathrm{O} 78: \mathrm{K} 80$. Besides, lots of international studies also showed that $\mathrm{O} 1, \mathrm{O} 2, \mathrm{O} 8$, $\mathrm{O} 18$ and $\mathrm{O} 78$ were detected more frequently in chickens, turkeys or other birds (Ewers et al., 2004, 2007; McPeake et al., 2005; Vandekerchove et al., 2005; Yaguchi et al., 2007; Dziva and Stevens, 2008; Ozawa et al., 2008). There has been not much research on serotyping of $E$. coli from ducks, especially in the Mekong Delta. In this study, $\mathrm{O} 2$ and O78 APEC were firstly reported from ducks in Vietnam. The results suggested that distribution of APEC O-serogroups from ducks in Vietnam are very complex and different from hosts and geographic regions. These problems cause difficulties in disease prevention by vaccine. Further work is needed to verify distribution of O-serogroup from different origins and different hosts.

Table 4: Results of antibiotic susceptibility tests from $E$. coli isolates $(n=659)$

\begin{tabular}{|c|c|c|c|c|c|c|c|}
\hline \multirow{2}{*}{ Antibiotic(s) } & \multirow{2}{*}{ Abb } & \multicolumn{2}{|c|}{ Resistant } & \multicolumn{2}{|c|}{ Intermediate } & \multicolumn{2}{|c|}{ Sensitive } \\
\hline & & No. & $(\%)$ & No. & $(\%)$ & No. & $(\%)$ \\
\hline Ampicillin & Am & 421 & $63.9^{* *}$ & 0 & 0.0 & 238 & 36.1 \\
\hline Trimethoprim + Sulfamethoxazole & $\mathrm{Bt}$ & 444 & $67.4^{* *}$ & 0 & 0.0 & 215 & 32.6 \\
\hline Norfloxacin & No & 133 & 20.2 & 169 & 25.6 & 357 & 54.2 \\
\hline Streptomycin & $\mathrm{Sm}$ & 434 & $65.9^{* *}$ & 0 & 0.0 & 225 & 34.1 \\
\hline Amikacin & $\mathrm{Ak}$ & 20 & 3.0 & 153 & 23.2 & 486 & $73.7^{*}$ \\
\hline Fosfomycin & Fos & 42 & 6.4 & 169 & 25.6 & 448 & 68.0 \\
\hline Doxycycline & Dx & 103 & 15.6 & 153 & 23.2 & 403 & 61.2 \\
\hline Cefuroxime & $\mathrm{Cu}$ & 102 & 15.5 & 322 & 48.9 & 235 & 35.7 \\
\hline Gentamycin & $\mathrm{Ge}$ & 143 & 21.7 & 101 & 15.3 & 415 & 63.0 \\
\hline Colistin & Co & 64 & 9.7 & 0 & 0.0 & 595 & $90.3^{* *}$ \\
\hline Florfenicolisepi & $\mathrm{FFc}$ & 134 & 20.3 & 401 & 60.8 & 124 & 18.8 \\
\hline
\end{tabular}

Prevalence in the same column with * is significant difference at level $(P=<0.05)$ and with $* *(P=<0.001)$

Abb: Abbreviation

Antibiotics have been used extensively for treatment of poultry diseases since 1950s. Occurring in parallel with use of an antimicrobial has been in progressive development of resistance which was initially identified following introduction of tetracyclines (Sojka, 1965). In recent years, the acceleration of antibiotic resistance in $E$. coli bacteria has been reported in many countries including Viet Nam (Thi Thu Hao Van et al., 2007; Price et al., 2013; Nguyen Thi Nhung et al., 2017). Therefore, it is very important to examine the susceptibility of these microorganisms involved in the disease outbreaks in order to avoid choosing ineffective antibiotics. In this study, APEC isolates demonstrated moderate to high resistance $(20.2 \%$ to $67.5 \%)$ to $7 / 15$ antibiotics (No, FFc, Ge, Te, Am, Sm and Bt), and the strongest resistance were to trimethoprim/ sulfamethoxazole $(67.4 \%)$ and streptomycin (65.9\%). These results are quite similar to many reports on $E$. coli antibiotic resistance in Vietnam and other countries (Truong Ha Thai et al., 2017; Miles et al., 2006; Vandemaele et al., 2002). The long use and misuse of antibiotics have contributed to the emergence and spread of antimicrobial resistant microorganisms (Levy, 1994). Besides, increasing uses of antibiotics as additives in poultry feed for growth promotion and disease preventive purposes lead to selective pressure for antibiotic resistance in bacteria in poultry, and it has been rapidly increased (Van den Bogaard et al., 2011). Colistin is a highly affective antibiotic against $E$. coli and has been commonly used for animal colibacillosis prevention and treatment, so there have been many reports about the resistance of E. coli to this antibiotic (Nguyen Thi Nhung et al., 2015; Truong Ha Thai et al., 2017). However, this study results revealed that high percentage of APEC $(90.3 \%)$ was sensitive to colistin. This matter can be explained by high sensitivity of ducks to this antibiotic so that it was rarely used in treatment and prevention duck diseases. Fosfomycin and amikacin are novel antibiotics, they have been introduced and come into commercial uses in the 1970s (Hendlin et al., 1969; Gilbert, 1995), and there are not many commercial products of two antibiotics which have been used in veterinary medicine in Vietnam, so the rates of APEC resisting to these antibiotics were still low (6.4\% and $3.0 \%$, respectively); especially, all amikacin products are injection forms and only used for mammals. These results are evidence of long antibiotic usage being a contributing factor to antimicrobial resistance. Although ciprofloxacin has been prohibited in using for animals, duck raisers can easily purchase it at pharmacy counters or chemical shops. This explains why there were not many $E$. 
coli isolates (40.2\%) showed susceptible to ciprofloxacin. This problem suggested a strict law in trading antibiotic must be applied in order to prevent antimicrobial resistance and to preserve antibiotics for human disease treatment. Since antibiotic resistance and sensitivity of bacteria have no relationship with serogroups of bacteria, the susceptibility of $E$. coli in each $\mathrm{O}$ serogroup to antibiotics was not analyzed in this study.

\section{CONCLUSIONS}

Duck colibacillosis occurs frequently in the Mekong Delta with two predominant serogroups $\mathrm{O} 2$ and O78. There is emerging of drug resistance in APEC associated duck colibacillosis. APEC showed moderate to high resistance to a lot of antibiotics, but low resistance to amikacin and fosfomycin.

\section{REFERENCES}

Bauer, A.W., Kirby, W.M.M., Sherris, J.C. and Turck, M., 1966. Antibiotic susceptibility testing by a standardized single disk method. American J. Clin. Pathol., 36(3): 493-496.

Bryan, M., Finola, L., Marie, A., Ann, C. and Dores, M., 2013. Enterobacteriaceae. In: Edwards, R. (Ed.). Clinical veterinary microbiology, $2^{\text {nd }}$ Ed. Mosby Elsevier, Canada, pp. 239-274.

CLSI, Clinical and Laboratory Standards Institute, 2017. M100 performance standards for antimicrobial susceptibility testing, $27^{\text {th }}$ Ed. Clinical and Laboratory Standards Institute, USA, 250 pages.

Dang Thi Vui and Nguyen Ba Tiep, 2016. Isolation and Characterization of Escherichia coli in Bau and Dom Ducks at Dai Xuyen Duck Breeding and Research Center. Vietnam J. Agri. Sci., 14(12): 1894-1902 (in Vietnamese).

Dho-Moulin, M. and Fairbrother, J.M., 1999. Avian pathogenic Escherichia coli. Vet. Res. 30: 299-316.

Dziva, F. and Stevens, M.P., 2008. Colibacillosis in poultry: unravelling the molecular basis of virulence of avian pathogenic Escherichia coli in their natural hosts. Avian Pathol., 37(4): 355-366.

Ewers, C., Janssen, T., Kiessling, S., Philipp, H.C. and Wieler, L.H., 2004. Molecular epidemiology of avian pathogenic Escherichia coli (APEC) isolated from colisepticemia in poultry. Vet. Microbiol., 104: 91-101.

FAO, Food and Agriculture Organization of the United Nations, 2008. Poultry production systems in Viet Nam. Prepared by Nguyen Van Duc and T. Long. GCP/RAS/228/GER Working Paper No. 4. Rome, 22 pages.

Leibovitz, L., 1972. A Survey of the So-Called "Anatipestifer Syndrome". Avian Diseases, 16(4): 836-851.

Gilbert, D.N., 1995. Aminoglycosides. In: Mandell GL, Bennett JE, Dolin R, eds. Douglas and Bennett's principles and practice of infectious diseases. New York: Churchill Livingston, 279-301.
Hendlin, D., Stapley, E. O., Jackson, M., et al., 1969. Phosphonomycin, a new antibiotic produced by strains of Streptomyces, Science, 166(3901): 122123.

Levy, S.B., 1994. Balancing the drug resistance equation. Trends in Microbiology, 2(10): 341- 342.

McPeake, S.J., Smyth, J.A. and Ball, H.J., 2005. Characterisation of avian pathogenic Escherichia coli (APEC) associated with colisepticaemia compared to faecal isolates from healthy birds. Vet. Microbiol., 110: 245-253.

Miles, T.D., McLaughlin, W. and Brown, P.D., 2006. Antimicrobial resistance of $E$. coli isolated from broiler chickens and humans. BMC Vet. Res., 2(7): 1-9.

Nguyen Thi Lien Huong, 2017. Colibacillosis in Muscovy ducks and method of treatment and prevention. Special subject information in agriculture and rural development. National extension center, 03: 1-32. Accessed on May 10th, 2018. Available from http://www.mard.gov.vn (in Vietnamese).

Nguyen Thi Nhung, Chansiripornchai, N. and CarriqueMas, J.J., 2017. Antimicrobial Resistance in Bacterial Poultry Pathogens: A Review. Front. Vet. Sci., 4(126): 1-17.

Nguyen Trong Phuoc, 1997. The prevalence of E. coli infection of ducks in Long An province, Go Vap urban district, Ho Chi Minh city. Composition of veterinary medicine bachelor. Nong Lam University. Ho Chi Minh city, 54 pages (in Vietnamese).

Nguyen Xuan Binh, Nguyen Van Cuong, Le Thi Mai Khanh, Tran Xuan Hanh, To Thi Phan and Phung Duy Hong Ha, 2000. The examination results of Salmonella và $E$. coli infections in duck in Long An province (1997-2000). Vietnam J. Vet. Sci, 7(4): 2935 (in Vietnamese).

Ozawa, M., Harada, K., Kojima, A., Asai, T. and Sameshima, T., 2008. Antimicrobial susceptibilities, serogroups, and molecular characterization of avian pathogenic Escherichia coli isolates in Japan. Avian Diseases, 52: 392-397.

Price, L.B., Johnson, J.R., Aziz, M., et al., 2013. The Epidemic of Extended-Spectrum- $\beta$-Lactamase-Producing Escherichia coli ST131 is driven by a single highly pathogenic subclone, H30-Rx. J. American Microbiol. Soc., 4(6): 1-10.

Roshdy, H., Soad, A.E.A. and Mohamed, R., 2012. Incidence of $E$. coli in chickens and ducks in different governorates in Egypt. 1st Conference of Animal Health Research Institute Association, 420-426.

Ryan, B., Joiner, B.L. and Ryan, Jr.T.A., 2000. Minitab statistical software. Release 13. Duxbury Press.

Sojka, W.J., 1965. Escherichia coli in domestic animals and poultry. Commomwealth Agricultural Bureaux. Farnham Royal England, 231 pages.

Sojka, W.J. and Carnaghan, R.B.A., 1961. Escherichia coli infection in poultry. Res. Vet. Sci, 2: 340-352.

Thi Thu Hao Van, Moutafis, G., Linh Thuoc Tran and Coloe, P.J., 2007. Antibiotic resistance in food-borne 
bacterial contaminants in Vietnam. Appl. Environ. Microbiol., 73: 7906-7911.

To Minh Chau, Tran Thi Bich Lien and Nguyen Ngoc Hai, 2002. The results of isolation and sero-typing of E. coli in chickens, chicken eggs in some farms in Thu Duc in its neighbourhoods. Vietnam J. Vet. Sci, 9(2): 28 -31 (in Vietnamese).

Truong Ha Thai, Pham Hong Ngan and Cam Thi Thu $\mathrm{Ha}, 2017$. Antimicrobial resistance of E. coli and Salmonella isolated from egg at Hanoi city retail markets, Vietnam J. Agri. Sci, 15(6): 770-775 (in Vietnamese).

Van den Bogaard, A.E., London, N., Driessen, C.A.G.G. and Stobberingh, E.E., 2001. Antibiotic resistance of faecal Escherichia coli in poultry, poultry farmers and poultry slaughterers. J. Antimicrob. Chemother., 47: 763-771.
Vandekerchove, D., Vandemaele, F., Adriaensen, C., Zaleska, M., Hernalsteens, J.P. and De Baets, L., 2005. Virulence-associated traits in avian Escherichia coli: comparison between isolates from colibacillosis-affected and clinically healthy layer flocks. Vet. Microbiol., 108: 75-87.

Vandemaele, F., Vereecken, M., Derijcke, J., and Goddeeris, B.M., 2002. Incidence and antibiotic resistance of pathogenic Escherichia coli among poultry in Belgium. Vet. Rec., 151: 355-356.

Vo Thi Tra An, Dao Thi Phuong Lan, Le Huu Ngoc and Nguyen Ngoc Tuan, 2010. Antibiotic resistance of $E$. coli in domestic animals and presence of extendedspectrum beta-lactamases (ESBL). Vietnam J. Agri. Sci, 17(2): 42-46 (in Vietnamese). 